Special issue of the 3rd International Conference on Computational and Experimental Science and Engineering (ICCESEN 2016)

\title{
Cross-Drainage Culvert Design by Using GIS
}

\author{
M. GÜNAL*, M. AY AND A.Y. GÜNAL \\ Uviversity of Gaziantep, Department of Civil Engineering, Gaziantep, Turkey
}

A culvert is a structure that allows water to flow under a road, railroad, trail, or similar obstruction, from one side to the other side. Typically embedded, so as to be surrounded by soil, a culvert may be made from a pipe, reinforced concrete or other material. In order to minimize the impact of a water crossing on the environment, culverts require the proper size, design and installation, to ensure that they do not cause downstream erosion, upstream flood, alter stream habitat or block organism passage. In this study, the size of a box culvert has been determined by getting more realistic maximum flow rates, by using data of a geographic information system. The results of this study have been compared with the rational method. The size of the culvert, which is calculated by using data from geographic information system will be more realistic and efficient, compared to the culvert, calculated by rational method.

DOI: 10.12693/APhysPolA.132.595

PACS/topics: 92.40.FB, 92.40.QP, 07.05.MH

\section{Introduction}

Cross-drainage culverts extend under roadways and transport runoff across the roadways. Design of roadcrossing culverts should take into account many engineering and technical aspects at the culvert site and the adjacent areas (Figs. 1, 2). The engineer must also incorporate personal experience and judgment, to determine which criteria must be considered and how to design the final dimensions of the culvert [1]. A drainage culvert should be designed according to design standards, that can safely drain the design peak flow.

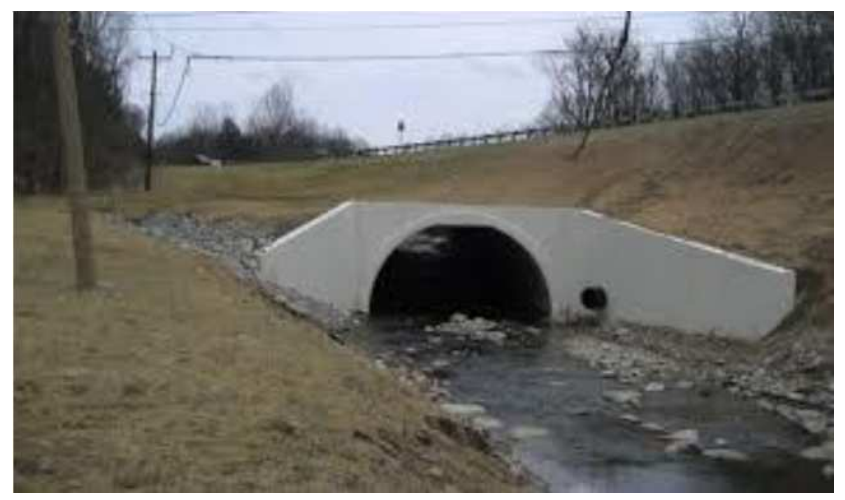

Fig. 1. Barrel culvert.

Norman et al. [2] compared several culvert design methods to find out the best design method. Culvert design methods are presented for both conventional culverts and culverts with inlet improvements. Muste et al. [3] conducted steady and unsteady flow laboratory measurements for a variety of culvert-barrel cross-section shapes

*corresponding author; e-mail: gunal@gantep.edu.tr and configurations, by using real-time data for discharge and water levels at several upstream and downstream locations of a culvert structure.

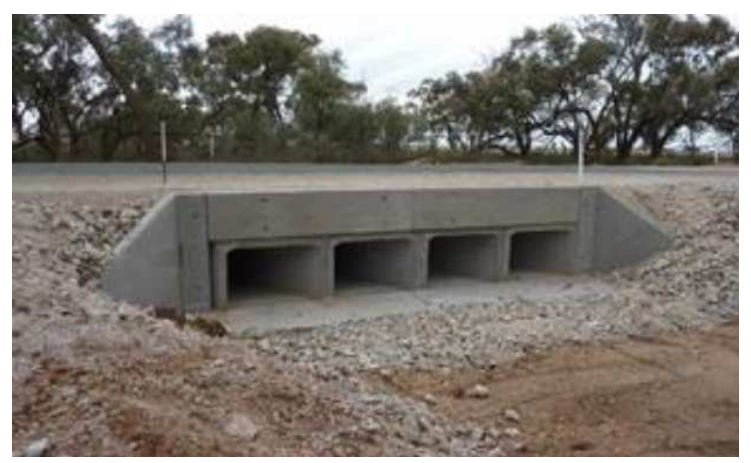

Fig. 2. Box culvert.

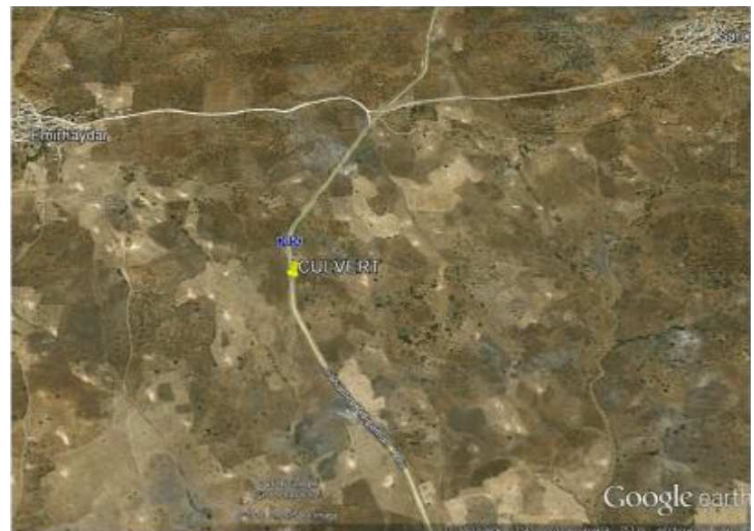

Fig. 3. Location of the drainage culvert.

This study focuses on designing a box culvert for 10 and 100 years maximum rainfall intensity, that was obtained from Gaziantep meteorology station, between Araban town of Gaziantep district and Besni town of Adiyaman district. The location of the centroid of culvert is at the $37^{\circ} 30^{\prime} 33^{\prime \prime}$ North latitude and the $37^{\circ} 42^{\prime} 23^{\prime \prime}$ East longitudes, as shown in Fig. 3. 


\section{Overview of geographical information system}

Geographical information system (GIS) is a powerful tool and is of great use for problem solving in many fields. In the 1970's and early 1980's, GIS mainly consisted of presenting maps on a display to support various types of geographically related information. GIS are becoming more and more widespread. Today most problems in engineering, such as geomorphologic parameters of a basin and forming synthetic hydrographs were studied by Günal and Güven $[4,5]$. GIS has been also a very important tool for making predictions. Günal and Kösen [6] applied GIS tool for predicting underground drinking water areas in Gaziantep region.

\section{Case study}

The culvert is located on D850 road, between Araban and Besni districts, in the region of South Anatolia of Turkey. The area of the culvert catchment is $5.55 \mathrm{~km}^{2}$. The boundary of catchment is extracted from the digital elevation map (DEM). The DEM was obtained from the NASA-EOSDIS (National Aeronautics and Space Administration's Earth Observing System Data and Information System), as shown in Fig. 4.

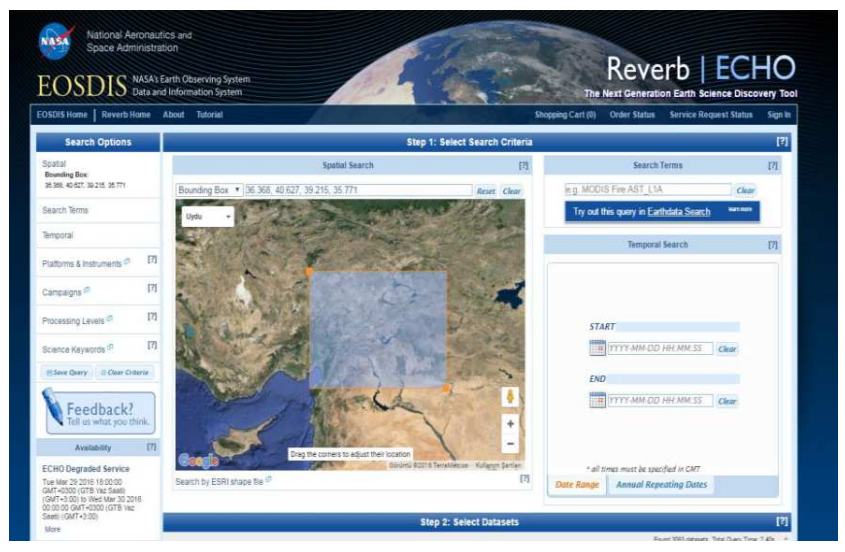

Fig. 4. DEM of the culvert catchment.

\subsection{Calculation of catchment area by using GIS}

Culvert catchment is determined by uploading DEM to ArcGIS program. The border of the catchment area is determined by entering the coordinates of the culvert. The catchment area was calculated to be $10.74 \mathrm{~km}^{2}$ and is shown in Fig. 5.

\subsection{Time of concentration calculation by using GIS}

The DEM of culvert basin is analyzed by Global Mapper V.16.1 and slopes of drainage lines are determined using ArcGIS program. The precipitation data belonging to Gaziantep district is loaded into ArcGIS program. The time of concentration for 10 and 100 years of occurrence are determined by using ArcGIS. The time of concentration output of the ArcGIS program is shown

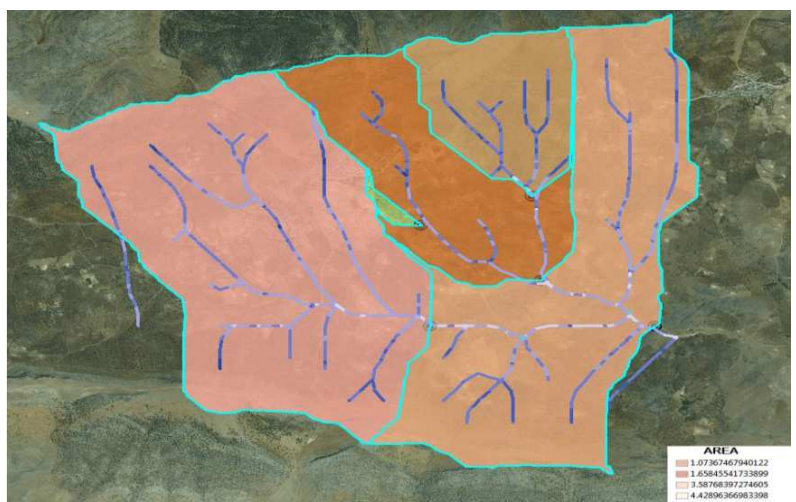

Fig. 5. Calculation of culvert catchment area.

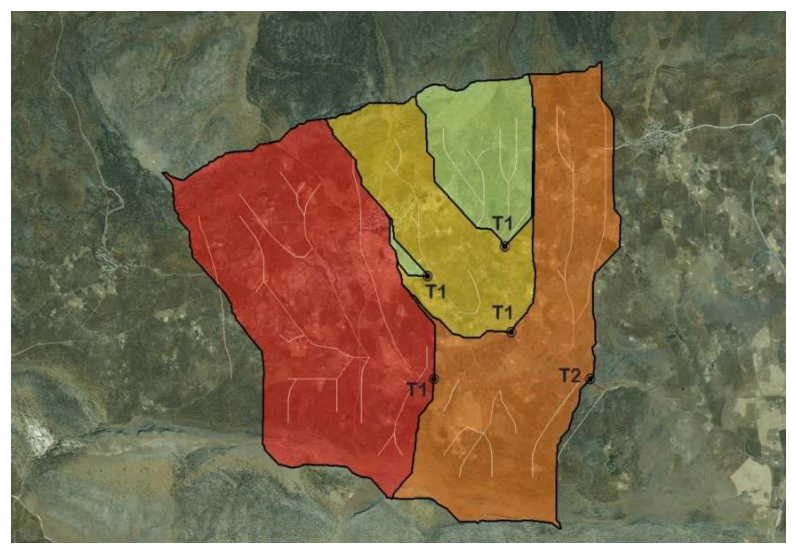

Fig. 6. Calculation of time of concentration.

in Fig. 6. The ArcGIS program has calculated time of concentration by using the following equations.

$$
\begin{aligned}
& T_{1}=L_{1} / V_{1} \times 60, \\
& T_{2}=0.0195\left(L_{2} / H_{2}\right)^{0.385},
\end{aligned}
$$

where, $T_{1}$ is flow time over the land, $L_{1}$ is flow length over the land and $V_{1}$ is flow velocity over the land, $T_{2}$ is flow time on drainage bed, $L_{2}$ is the length of drainage bed and $\mathrm{H}_{2}$ is elevation difference of drainage bed. Total time of concentration in minutes is calculated by summation of $T_{1}$ and $T_{2}$, as follows;

$$
T_{\mathrm{t}}=T_{1}+T_{2} .
$$

\subsection{Runoff coefficient}

The relationship between rainfall and runoff is determined by a dimensionless coefficient, known as runoff coefficient, that has a large value for areas with low permeability. In order to determine the annual runoff coefficient of a basin, the total annual stream flow is plotted against the total annual precipitation. The slope of the regression line is accepted to be the runoff coefficient (Fattah and Yuce [7]). The calculated runoff coefficient, which is a function of vegetation cover, degree of urbanization, climatological features and geological setting of the catchment area, plays a major role in the planning, design and operation of water resources projects in a catchment (Kadioglu and Şen [8], Sen and Altunkaynak [9], La Torre 
Torres et al. [10], Raji et al. [11]). In this study, runoff coefficient $C$ is calculated to be 0.12 , which is a commonly used value for forest areas.

\subsection{Peak flow calculation by using GIS}

After entering the rainfall-intensity curve from the Gaziantep meteorology station into the ArcGIS program, the surface flow rate was calculated according to Eq. (4). The calculated surface flow rates for 10 and 100 years of rainfall intensity $I$ are shown in Figs. 7 and 8 .

$$
Q=C I A / 3600 \text {, }
$$

where, $Q$ is flow rate $\left(\mathrm{m}^{3} / \mathrm{s}\right), A$ is basin area $\left(\mathrm{m}^{2}\right), C$ is runoff coefficient and $I$ is rainfall intensity $(\mathrm{m} / \mathrm{hr})$.

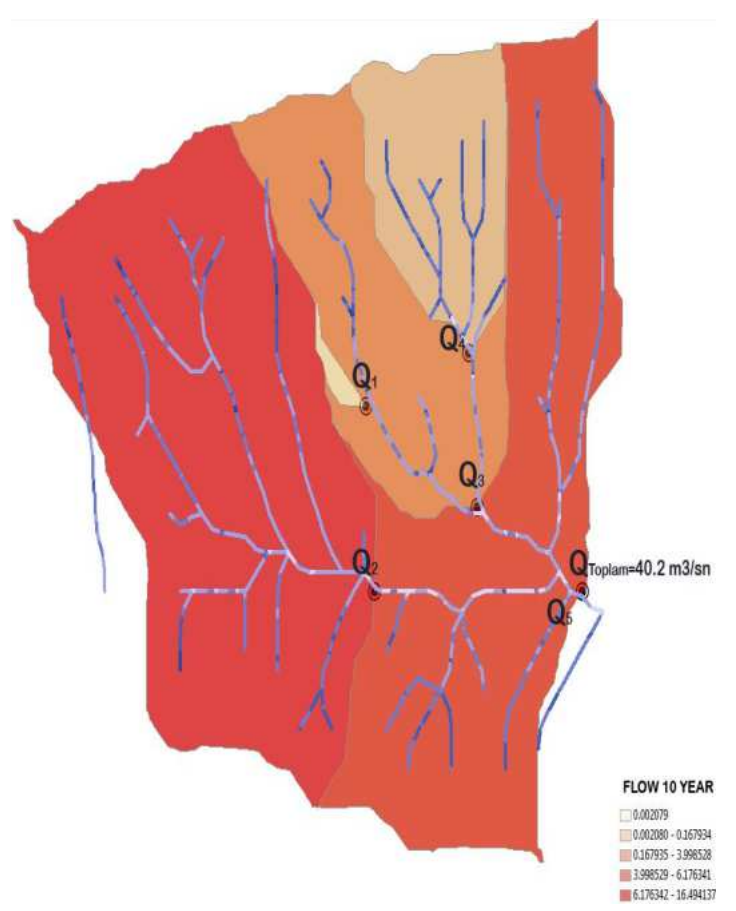

Fig. 7. Surface flow rate $Q$, calculated using GIS for 10 years.

\subsection{Culvert dimensions}

The Manning equation is used to calculate the diameter of culvert (Rothwell [12]), as follows:

$$
D=\left(\frac{Q^{3 / 4} n^{3 / 4}}{S^{3 / 4} \pi^{3 / 4}}\right),
$$

where, $D$ is culvert diameter $(\mathrm{m}), S$ is culvert slope $(\mathrm{m} / \mathrm{m})$, value of 0.015 was selected by default, $n$ is roughness coefficient of culvert, which was set to 0.021 (Chow [13]), $Q$ is discharge $\left(\mathrm{m}^{3} / \mathrm{s}\right)$, obtained from Eq. (4).

\section{Comparison of rational method and GIS model}

The discharges calculated with relation method (General Directorate of Highway Approach) and discharges calculated using GIS model are shown in Table I.

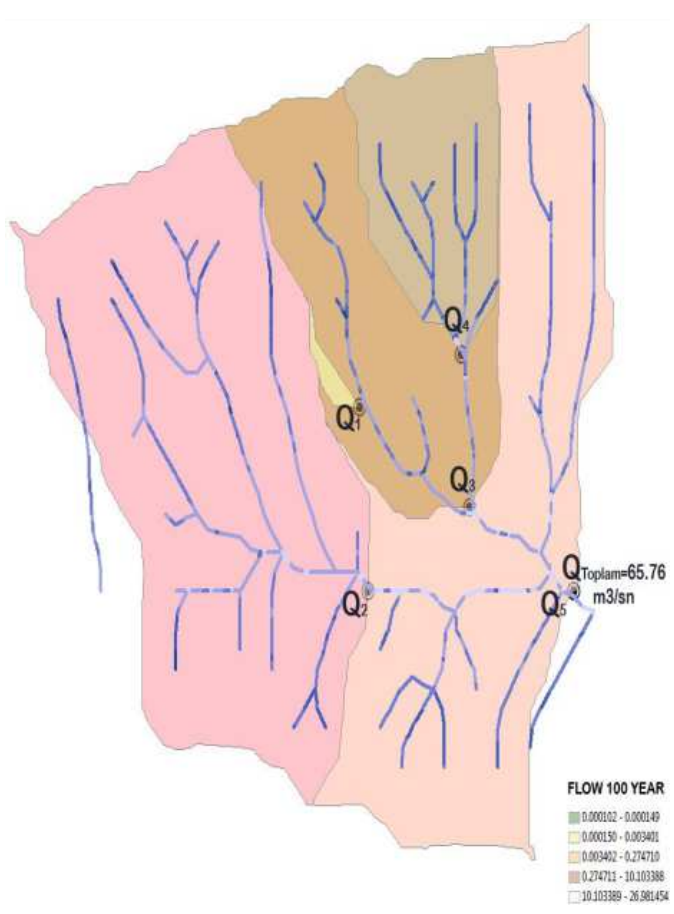

Fig. 8. Surface flow rate $Q$, calculated using GIS for 100 years.

TABLE I

Calculated and predicted discharges.

\begin{tabular}{c|c|c|c|c}
\hline \hline & $\begin{array}{c}\mathrm{Q}_{10} \\
{\left[\mathrm{~m}^{3} / \mathrm{s}\right]}\end{array}$ & $\begin{array}{c}\mathrm{Q}_{100} \\
{\left[\mathrm{~m}^{3} / \mathrm{s}\right]}\end{array}$ & $\begin{array}{c}\text { Box } \\
\text { number }\end{array}$ & $\begin{array}{c}\text { Box size } \\
{[\mathrm{m}]}\end{array}$ \\
\hline $\begin{array}{c}\text { Relation method } \\
\text { GIS }\end{array}$ & 26.8 & 43.84 & 2 & $(3.0 \times 3.0)$ \\
& 40.2 & 65.76 & 2 & $(4.5 \times 4.5)$
\end{tabular}

It is seen from Table I that there are some differences between discharges calculated using two methods. The discharge of GIS method seems to be larger by $50 \%$ for both discharges of 10 and 100 years of return period. This is because in rational method, some of the parameters are approximated and assumed according to handbook of General Directorate of Highway, but in GIS method, the program takes the values from the digital map using most updated values of geomorphologic parameters.

The culvert design in rational method is done by considering the contour lines, which are crucial in area calculation. In ArcGIS program, the area calculation is done directly using the satellite map. A surface survey is performed and the calculations for the box culvert design are done according to the ground elevation and area is computed without the error.

\section{Conclusions}

The discharge values of GIS method were $50 \%$ larger than the discharge values of rational method for both 10 and 100 years return period. The advantage of rational method, giving lower dimensions, is the lower cost 
of the construction of the culvert, and the disadvantage is caused by the fact, that some parameters are approximated. In extreme climate conditions the capacity of the constructed culvert might be not enough to carry out the collected water, which can let the water to cross over and so, to damage the roadway. It is also concluded that GIS method is more trustworthy than the rational method, because of using the real digital maps.

\section{References}

[1] M.S. Kanga, J.H. Koob, J.A. Chunc, Y.G. Herd, S.W. Parka, K. Yooe, Biosystems Eng. 104, 425 (2009).

[2] J.M. Norman, R.J. Houghtalen, W.J. Johnson, Hydraulic Design of Highway Culverts, 2nd ed., 2001.

[3] M. Muste, H.C. Ho, D. Mehl, Insights into the Origin and Characteristics of the Sedimentation Process at Multi-Barrel Culverts in Iowa in: Technical report IHRB project TR-596, The Iowa Highway Research Board, 2010.

[4] A.Y. Günal, A. Güven, Acta Phys. Pol. A 128, B-222 (2015).
[5] A.Y. Günal, A. Güven, Acta Phys. Pol. A 130, 130 (2016).

[6] M. Günal, A. Kösen, Acta Phys. Pol. A 128, B-107 (2015).

[7] W.H. Fattah, M.I. Yuce, Int. J. Appl. Sci. Technol. 5, 47 (2015).

[8] M. Kadioglu, Z. Şen, Hydrological Sci. J. 46, 3 (2001).

[9] Z. Sen, A. Altunkaynak, Hydrol. Process. 20, 1993 (2006).

[10] I.B. La Torre Torres, D.M. Amatya, G. Sun, T.J. Callahan, Hydrol. Proc. 25, 2032 (2011).

[11] P. Raji, E. Uma, J. Shyla, Agricult. Engin. Int.: CIGR J. 13, 1 (2011).

[12] R.L. Rothwell, Watershed Management Guidelines for Logging and Road Construction in Alberta, Information Report NOR-X-198, Northern Forest Research Centre, Canadian Forest Service, 1978.

[13] V.T. Chow, Open-Channel Hydraulics, McGraw-Hill Book Company, New York 1959. 